\title{
Relativiteitsperikelen: Wet wapens en munitie geen schild tegen concrete (vermogens)schade?
}

\author{
Mr. R. Meijer*
}

\begin{abstract}
1 Inleiding
Het Nederlandse aansprakelijkheidsrecht gaat uit van een relatieve onrechtmatigheid. Het enkele feit dat iemand een rechtsnorm schendt met als gevolg dat bepaalde personen schade lijden, betekent nog niet direct dat de normschender aansprakelijk is jegens alle personen die schade hebben geleden als gevolg van die normschending. Er bestaat slechts aansprakelijkheid jegens de benadeelden als de schadeveroorzaker jegens de specifieke benadeelde personen onrechtmatig heeft gehandeld en de geschonden norm strekt tot bescherming van de schade zoals deze is geleden (het relativiteitsvereiste). ${ }^{1}$
\end{abstract}

In veel gevallen vormt het relativiteitsvereiste geen belemmering bij het aannemen van aansprakelijkheid, of is, als dat wel het geval is, min of meer duidelijk dat de geschonden norm inderdaad niet de strekking heeft de benadeelde personen te beschermen. Uiteraard zullen er ook altijd twijfelgevallen zijn. De rechter zal hier op zoek moeten gaan naar het beschermingsoogmerk van de geschonden norm en op basis daarvan de knoop moeten doorhakken. Hoewel de uitkomst van het onderzoek naar het beschermingskarakter en de omvang daarvan niet altijd even voorspelbaar is - ook omdat de wetgever meestal niet expliciet aangeeft welke personen bescherming kunnen ontlenen aan een specifieke norm - kan niet worden gezegd dat het relativiteitsbeginsel in de praktijk een veelvoorkomende hobbel is waarop een aansprakelijkheidsvordering strandt. Dit ligt echter genuanceerder als het gaat om aansprakelijkheidsclaims tegen de overheid. Er zijn de laatste jaren verschillende zaken geweest waar een aansprakelijkheidsvordering tegen de overheid stukliep op het ontbreken van relativiteit. $^{2}$ Daarbij valt op dat er in die zaken betrekkelijk strenge

* Mr. R. Meijer is advocaat bij ZIPPRO \& MEIJER Advocaten te Amsterdam en universitair docent bij het Molengraaff Instituut van de Universiteit Utrecht.

1. Art. 6:163 BW: 'Geen verplichting tot schadevergoeding bestaat, wanneer de geschonden norm niet strekt tot bescherming tegen de schade zoals de benadeelde die heeft geleden.'

2. Zie bijv. HR 7 mei 2004, ECLI:NL:HR:2004:AO6012, NJ 2006/281 (Duwbak Linda) en HR 13 april 2007, ECLI:NL:HR:2007:AZ8751, NJ 2008/576 (Iraanse vluchtelinge). eisen worden gesteld aan het vervuld zijn van het relativiteitsvereiste. ${ }^{3}$

De recente uitspraak van de Rechtbank Den Haag van 4 februari 2015 in de procedure van de slachtoffers (dan wel hun erfgenamen) (hierna: de Slachtoffers) van het schietdrama in Alphen aan den Rijn tegen de politieregio Hollands Midden (hierna: PHM) past in dit rijtje van zaken waar de overheid met succes een beroep doet op het ontbreken van relativiteit. In deze uitspraak wijst de rechtbank de aansprakelijkheid van PHM af omdat de Wet wapens en munitie (WWM) niet de strekking heeft de slachtoffers te beschermen tegen schade die is ontstaan door de schietpartij met behulp van wapens waarvoor ten onrechte een vergunning is afgegeven. In deze bijdrage worden, na het oordeel van de rechtbank te hebben geschetst (par. 2), enkele kanttekeningen geplaatst bij deze uitspraak van de rechtbank van 4 februari 2015 (par. 3).

\section{Vonnis van de Rechtbank Den Haag van 4 februari 2015}

\subsection{Feiten}

Op 9 april 2011 heeft er in en rond winkelcentrum de Ridderhof in Alphen aan den Rijn een schietpartij plaatsgevonden waarbij zes mensen om het leven zijn gekomen en zestien gewonden zijn gevallen. De Slachtoffers zijn (onder meer) een aansprakelijkheidsprocedure gestart tegen PHM. Volgens de Slachtoffers heeft PHM onrechtmatig gehandeld omdat zij niet had mogen overgaan tot het verlenen van een wapenvergunning aan de dader van de schietpartij, Tristan van der Vlis (hierna: Van der Vlis), en ten onrechte niet alle relevante feiten heeft betrokken bij de beoordeling van de aanvraag van de wapenvergunning. Dit levert volgens de Slachtoffers een onrechtmatige daad op wegens handelen in strijd met zowel de WWM als de maatschappelijke betamelijkheid. Tevens beroepen de Slachtoffers zich op de positieve verplichtingen die voortvloeien uit het Europees Verdrag tot bescherming van de

3. Zie over het relativiteitsvereiste en de toepassing daarvan bij overheidsaansprakelijkheid, L. di Bella, De toepassing van de vereisten van causaliteit, relativiteit en toerekening bij de onrechtmatige overheidsdaad (diss. Leiden), Deventer: Kluwer 2014. 
rechten van de mens en de fundamentele vrijheden (EVRM), die volgens de Slachtoffers inhouden dat als de overheid weet of had moeten weten dat burgers gevaar lopen door toedoen van een andere burger, de overheid alle maatregelen moet nemen die redelijkerwijs kunnen worden gevergd ter bescherming van het leven van de burger die gevaar loopt.

\subsection{Toetsingskader verlenen wapenvergunning}

De rechtbank schetst in zijn vonnis uitvoerig het toetsingskader voor de procedure bij het verlenen van een wapenvergunning krachtens het stelsel van de WWM en de Circulaire wapens en munitie (CWM). De WWM geeft uitdrukking aan het geweldsmonopolie van de overheid doordat de WWM de kring van personen die over wapens en munitie mogen beschikken, beperkt. Het is burgers verboden wapens en munitie voorhanden te hebben, tenzij daar verlof voor is verleend. Dit verlof wordt op grond van art. 28 WWM bovendien slechts verleend indien (1) een redelijk belang de verlening van het verlof vordert en (2) de aanvrager geen gevaar voor zichzelf, de openbare orde of veiligheid kan vormen. De rechtbank verwijst in dit verband naar de wetsgeschiedenis bij art. 28 WWM, waaruit volgt dat niet snel wordt aangenomen dat een redelijk belang het vordert dat een burger een pistool of revolver voorhanden heeft. Uit dezelfde wetsgeschiedenis volgt overigens wel dat serieuze beoefening van de schietsport een zodanig redelijk belang kan opleveren (Van der Vlis was lid van een schietvereniging).

In art. 7 WWM staan de weigeringsgronden voor de aanvraag voor een wapenvergunning. De gevraagde vergunning wordt onder meer geweigerd als er reden is om te vrezen dat (1) aan de aanvrager het onder zich hebben van wapens of munitie niet kan worden toevertrouwd of (2) van de wapens of munitie misbruik zal worden gemakkt. De rechtbank wijst erop dat uit de memorie van toelichting volgt dat er hier geen beleidsvrijheid bestaat. Wanneer er reden is om te vrezen voor misbruik, dan zal, zelfs als er wel sprake is van een redelijk belang, tot weigering moeten worden overgegaan. Daarbij wordt volgens de CWM aan de 'vrees voor misbruik' een ruime uitleg gegeven en valt daaronder ook het geval waarin de aanvrager een gevaar voor zichzelf, de openbare orde of veiligheid kan vormen. De CWM stelt expliciet dat vanwege de potentieel ernstige bedreiging voor de veiligheid in de samenleving indien wapens in handen komen van personen die onvoldoende betrouwbaar zijn om een wapen voorhanden te hebben, er een restrictief beleid moet worden gevoerd bij het aannemen dat er geen vrees voor misbruik is. Ten behoeve van de bescherming van de veiligheid van de maatschappij is reeds geringe twijfel voldoende om een vergunning niet te verlenen. Aan deze geringe twijfel dient wel een objectief toetsbare motivering ten grondslag te liggen. Het gaat met andere woorden om geobjectiveerde geringe twijfel.

\subsection{Onrechtmatig handelen}

De rechtbank oordeelt dat bij de behandeling van de aanvraag van Van der Vlis voor een wapenvergunning niet alle relevante beschikbare gegevens zijn betrokken en dat PHM inderdaad in strijd heeft gehandeld met de WWM. In het bijzonder is in de besluitvorming niet meegenomen dat er al in 2003 incidenten waren geweest met een luchtbuks en dat een eerdere aanvraag voor een wapenvergunning op basis van deze luchtbuksincidenten was geweigerd. Ook was een opname van Van der Vlis op grond van de Wet bijzondere opnemingen in psychiatrische ziekenhuizen uit 2006 (hierna: Bopz-opname) buiten beschouwing gelaten. Het betrof de inbewaringstelling van Van der Vlis in een psychiatrisch ziekenhuis in verband met suicidaliteit. PHM had assistentie verleend in verband met deze opname.

Indien PHM wel alle relevante informatie had meegewogen, dan had dit volgens de rechtbank tot een voorgenomen weigering van de gevraagde wapenvergunning moeten leiden. De rechtbank oordeelt verder dat deze voorgenomen weigering ook tot een definitieve weigering had geleid. De rechtbank acht het namelijk buiten redelijke twijfel dat Van der Vlis geen verklaring van een behandeld arts/psychiater had kunnen overleggen waaruit zou blijken dat zijn probleem niet (langer) een belemmering vormde hem een wapenvergunning te verlenen. In dit verband verwijst de rechtbank naar een rapport dat is opgesteld door de Inspectie voor de Gezondheidszorg. Het voornemen tot weigering was daarom volgens de rechtbank hoe dan ook gevolgd door een weigeringsbesluit. Het verzuim niet alle bekende informatie te betrekken bij de vergunningverlening heeft dus geleid tot het ten onrechte verlenen van een wapenvergunning. Dit levert een onrechtmatige daad op wegens handelen in strijd met een wettelijke plicht.

\subsection{Beschermingsbereik WWM}

Kortom, PHM heeft inderdaad fouten gemaakt bij de vergunningverlening en heeft hiermee onrechtmatig gehandeld. Deze onrechtmatigheid resulteert echter niet in aansprakelijkheid van PHM jegens de Slachtoffers. Volgens de rechtbank strekt de geschonden norm, de WWM, namelijk niet tot bescherming tegen de schade van de Slachtoffers. De rechtbank stelt hierbij voorop dat bij beantwoording van de vraag of aan het relativiteitsvereiste in de zin van art. 6:162 van het Burgerlijk Wetboek (BW) is voldaan, het aankomt op het doel en de strekking van de geschonden norm. Aan de hand daarvan moet vervolgens worden vastgesteld tot welke personen en schade de bescherming van de norm zich uitstrekt.

Volgens de rechtbank geeft de WWM vorm aan het geweldsmonopolie van de overheid als het gaat om wapens en munitie. Met een verwijzing naar de memorie van toelichting van de wetgever bij de WWM tekent de rechtbank aan dat de wet verschillende doeleinden dient, waaronder de bescherming van de veiligheid van burger en Staat. Verder is door de wetgever verwezen naar de behoefte aan strenge controle voor het bezitten en dragen van wapens en een effectieve controle van wapenhandel. 
Op basis van deze aan de wetsgeschiedenis ontleende doeleinden van de WWM brengt de rechtbank een onderscheid aan tussen enerzijds de door de WWM nagestreefde algemene maatschappelijke norm van de veiligheid van de samenleving en anderzijds de door PHM geschonden norm door onvoldoende zorgvuldig te zijn geweest in de besluitvorming bij de vergunningverlening. Hoewel de rechtbank onderkent dat deze geschonden norm bijdraagt aan verwezenlijking van de algemene (veiligheids)norm, is daarmee volgens de rechtbank niet gezegd dat de in de CWM neergelegde en uit de WWM voortvloeiende eisen van zorgvuldigheid van de besluitvorming over een wapenvergunning mede strekken ter bescherming van de (vermogens)schade die de Slachtoffers hebben geleden doordat Van der Vlis wapens waarvoor ten onrechte een vergunning was verleend, heeft gebruikt bij het schietincident.

\section{Daarbij overweegt de rechtbank dat: ${ }^{4}$}

'voor zover misbruik al moet worden gezien als een algemeen voorzienbaar gevolg van onzorgvuldige besluitvorming die leidt tot het ten onrechte verlenen van een wapenverlof, alleen al vanwege de grote verscheidenheid van mogelijke vormen van misbruik met uiteenlopende gevolgen, onzorgvuldige besluitvorming een onbepaalde en in beginsel onbegrensde groep potentiële gelaedeerden raakt, die op niet in algemene zin te voorziene wijze tot velerlei vorm van schade zou kunnen leiden'.

De rechtbank is voorts van oordeel dat niets in de totstandkomingsgeschiedenis van de WWM erop wijst dat met de door PHM geschonden norm is beoogd individuele vermogensbelangen van welke aard dan ook te beschermen. Daarbij acht de rechtbank ook van belang dat uit het stelsel van rechtsbescherming ten aanzien van de vergunningverlening volgt dat er slechts een beperkte kring van beroepsgerechtigden is die bezwaar kan maken tegen een (voorgenomen) weigering of verlening van een wapenvergunning. Ook verder bevat de WWM volgens de rechtbank geen bepalingen waaraan de individuele burger rechtstreeks rechten kan ontlenen indien hij vreest dat er door een te verlenen of verleende wapenvergunning gevaar voor zijn leven ontstaat, en de WWM bevat ook geen regeling waaraan de burger bescherming ontleent als zijn veiligheid door het wapengebruik door een ander in gevaar is gekomen en hij daardoor schade heeft geleden.

De slotsom van de rechtbank is dat de door PHM bij de wapenvergunning geschonden norm niet mede strekt tot bescherming van de individuele vermogensbelangen van de Slachtoffers.

\subsection{Strijd met ongeschreven zorguuldigheidsnorm}

Het beroep van de Slachtoffers op schending van een ongeschreven zorgvuldigheidsnorm wordt ook afgewezen door de

4. R.o. 5.43 rechtbank. De rechtbank wijst erop dat de in art. 6:162 BW neergelegde zorgvuldigheidsnorm een relatieve norm is die verplicht tot zorgvuldigheid in verhouding tegenover één of meer anderen. Een veilige samenleving is naar het oordeel van de rechtbank weliswaar in het belang van eenieder en is in zoverre een kenbaar belang, maar dit brengt niet mee dat onzorgvuldige besluitvorming bij de vergunningverlening per definitie leidt tot schending van een zorgvuldigheidsnorm jegens eenieder. Doorslaggevend is welk specifiek belang in het concrete geval kenbaar was voor PHM. Bij de inkleuring van deze zorgvuldigheidsnorm neemt de rechtbank tevens de door de Slachtoffers ingeroepen bepalingen van het EVRM in ogenschouw. Daarbij merkt de rechtbank onder meer op dat art. 2 EVRM niet het leven zelf beschermt, maar het recht op leven, welk recht geen garantie biedt op bescherming tegen alle gevaren van het leven.

De rechtbank is van oordeel dat PHM uit de gegevens die zij had moeten meewegen in de besluitvorming rondom de wapenvergunning, niet had hoeven afleiden dat willekeurige derden een veiligheidsrisico liepen indien Van der Vlis een wapenvergunning zou krijgen. Ook als PHM wel kennis zou hebben genomen van de eerdere weigering van de wapenvergunning in verband met de luchtbuksincidenten en de Bopzopname, had PHM volgens de rechtbank niet over geobjectiveerde kennis beschikt die wees op een veiligheidsrisico voor willekeurige derden bij verlening van een wapenvergunning aan Van der Vlis. De luchtbuksincidenten dateerden al van meer dan vijf jaar geleden en de Bopz-opname hield verband met suïcidaliteit en niet met gevaar voor wapenmisbruik jegens willekeurige derden. Er is daarom geen zorgvuldigheidsnorm jegens de Slachtoffers geschonden, aldus de rechtbank.

\section{Kanttekeningen}

De rechtbank wijst de vorderingen van de Slachtoffers af op het relativiteitsvereiste. Er is weliswaar in strijd gehandeld met een wettelijke plicht, maar deze wettelijke plicht zou niet strekken tot bescherming van de schade van de Slachtoffers. Evenmin is er in strijd gehandeld met een zorgvuldigheidsnorm jegens de Slachtoffers. De rechtbank motiveert dit oordeel uitvoerig met verwijzingen naar het stelsel van de WWM en de wetsgeschiedenis. Toch zijn er naar mijn mening enkele kanttekeningen te plaatsen bij (onderdelen van) het oordeel van de rechtbank.

\subsection{WWM: veiligheid in het algemeen of mede ter bescherming van individuele burgers?}

De rechtbank legt de WWM zo uit dat deze wet alleen betrekking heeft op het algemene belang van veiligheid en dat niets erop wijst dat de geschonden norm beoogt individuele vermogensbelangen van welke aard dan ook te beschermen. De rechtbank ontleent deze uitleg aan de wetsgeschiedenis van de WWM. Hoewel met de rechtbank moet worden gezegd dat de WWM inderdaad geen expliciete verwijzing bevat naar het oogmerk van bescherming van individuele burgers, moet worden vastgesteld dat het tegendeel ook niet kan worden 
beweerd. Er zijn geen concrete indicaties dat de wetgever heeft bedoeld concrete burgers die schade lijden door wapens waarvoor in strijd met de WWM een vergunning is verleend, uit te sluiten van bescherming.

Voorheen werd veelal aangenomen dat een norm in beginsel de strekking heeft tot bescherming van degenen die schade lijden als gevolg van de schending van de norm. Een vermoeden van relativiteit derhalve. Dit relativiteitsvermoeden werd gebaseerd op de parlementaire geschiedenis: ${ }^{5}$

'Evenals het ontwerp gaat ook het gewijzigd ontwerp ervan uit dat een norm in beginsel strekt ter bescherming van allen die als gevolg van overtreding ervan schade kunnen lijden en dat wel ter bescherming tegen alle schade die aan de dader op de voet van artikel 6.1.9.4 als een gevolg van die overtreding kan worden toegerekend. Voor een beroep op het onderhavige artikel moet derhalve komen vast te staan dat de betreffende norm de eiser in het gegeven geval niet beschermt tegen de schade, zoals hij deze heeft geleden.'

Op basis van de voornoemde passage zou een vordering alleen moeten stranden op het relativiteitsvereiste indien wordt geoordeeld dat de strekking van de norm niet is bescherming te bieden aan de benadeelden dan wel het type schade van de benadeelden. De rechtbank hanteert in het hier besproken vonnis echter een spiegelbeeldige toets: alleen als komt vast te staan dat de strekking van de geschonden norm wel is (mede) bescherming te bieden aan de Slachtoffers, is voldaan aan het relativiteitsvereiste.

Hoewel deze benadering op gespannen voet lijkt te staan met de parlementaire geschiedenis, vindt de aanpak van de rechtbank wel steun in verschillende arresten van de Hoge Raad. Zo heeft de Hoge Raad in het arrest Astrazeneca/Menzis duidelijk gemaakt dat het door Astrazeneca ingenomen standpunt dat de geschonden normen uit het Reclamebesluit geneesmiddelen en de Wet tarieven gezondheidszorg in beginsel beschermen tegen alle schade die Astrazeneca als gevolg van die schending lijdt, uitgaat van een onjuist uitgangspunt. ${ }^{6}$ Kortom, de Hoge Raad gaat daar niet uit van een relativiteitsvermoeden. In dit arrest gaat de Hoge Raad echter ook niet zo ver dat wordt verlangd dat er pas is voldaan aan het relativiteitsvereiste indien dit expliciet volgt uit de norm of toelichting daarop. Dat is echter wel wat de rechtbank in de onderhavige zaak lijkt te hebben gedaan.

Ook voor deze benadering is echter steun te vinden in arresten van de Hoge Raad. In dit verband kan bijvoorbeeld worden gewezen op het arrest Duwbak Linda, waar het ging om de aansprakelijkheid van de Staat voor schade die was ontstaan

5. Parl. Gesch. Boek 6, p. 638.

6. HR 10 november 2006, NJ 2008/491 (Astrazeneca/Menzis). door een gezonden duwbak (de 'Linda'). ${ }^{7}$ Deze duwbak had (ten onrechte) een goedkeuringscertificaat ontvangen van de scheepvaartinspectie ondanks dat de duwbak in zeer slechte staat verkeerde. De Hoge Raad oordeelt in dat arrest dat niet is voldaan aan het relativiteitsvereiste omdat uit de geschonden regelgeving en de toelichting daarop niet kan worden afgeleid dat deze mede strekken tot bescherming van het individuele vermogensbelang van derden. De Hoge Raad maakt in het arrest Duwbak Linda ook een onderscheid tussen de algemene norm die strekt tot het bevorderen van de veiligheid in algemene zin van het scheepvaartverkeer en de zorgvuldigheidsnorm die in acht moeten worden genomen bij de keuring van de schepen. Dit onderscheid komt ook in het onderhavige vonnis van de Rechtbank Den Haag terug. Het verschil tussen de casus die ten grondslag lag aan het arrest Duwbak Linda en de vordering tegen PHM is wel dat het bij (een aantal van) de Slachtoffers in de procedure tegen PHM gaat om letselschade. Dit zou aanleiding kunnen zijn om uit te gaan van een ruimer beschermingsbereik. In de commentaren bij het arrest Duwbak Linda werd ook wel opgemerkt dat het anders zou kunnen liggen als het zou gaan om letselschade. ${ }^{8}$ De rechtbank lijkt de aard van de schade echter niet mee te wegen in het oordeel over relativiteit.

Het vonnis is dus op zichzelf in lijn met de meer stringente benadering van relativiteit bij overheidsaansprakelijkheid, zoals deze het laatste decennium lijkt te zijn ingezet. ${ }^{9}$ Uiteindelijk gaat het hier om de rechtspolitieke keuze dat de deur voor overheidsaansprakelijkheid niet te ver moet worden opengezet. Met name niet in gevallen waar de overheid weliswaar in strijd heeft gehandeld met de op haar rustende wettelijke verplichtingen en causaal betrokken is bij het ontstaan van de schade (hier: PHM door ten onrechte een wapenvergunning te verlenen), maar niet de directe schadeveroorzaker is (dat is hier Van der Vlis).

Als deze lijn van jurisprudentie - waarbij in het geval van overheidsaansprakelijkheid voor vervulling van het relativiteitsvereiste nodig is dat er concrete en zelfs expliciete aanwijzingen zijn dat de strekking van de norm is de benadeelden te beschermen tegen de geleden schade - zich doorzet, kan wel de vraag worden gesteld of de wetgever bij de totstandkoming van wetten niet meer aandacht zou moeten gaan besteden aan de beschermingsomvang van de uitgevaardigde normen. Juist omdat dit meestal niet gebeurt, is in het verleden immers gekozen voor het uitgangspunt van de aanwezigheid van een beschermingskarakter, tenzij - negatief - blijkt dat de strekking van de norm een andere is. ${ }^{10} \mathrm{Als}$ dit uitgangspunt wordt losgelaten (bij overheidsaansprakelijkheid), moet hier vanuit wetgevingsperspectief wellicht ook een verandering plaatsvinden. Probleem hierbij is natuurlijk wel dat het niet eenvoudig

7. HR 7 mei 2004, ECLI:NL:HR:2004:AO6012, NJ 2006/281 (Duwbak Linda).

8. G.E. van Maanen, NTBR 2004/9, p. 483.

9. Zie hierover o.m. Di Bella 2014.

10. Parl. Gesch. Boek 6, p. 626. 
- en in veel gevallen zelfs onmogelijk - is bij voorbaat (alle) door de norm beschermde belangen te formuleren. Het is echter wel mogelijk om bij de totstandkoming op een meer algemeen niveau aan te geven wat de beschermingsstrekking is, zonder dat dit meteen een uitputtende opsomming is.

\subsection{Kring van beroepsgerechtigden}

De rechtbank onderbouwt het ontbreken van het beschermingsbereik van de WWM voor de Slachtoffers ook met een verwijzing naar de beperkte kring van beroepsgerechtigden waarvoor op grond van art. 34 WWM administratief beroep openstaat tegen een beschikking op grond van de WWM. De kring van belanghebbenden in de zin van art. 1:2 (het vonnis verwijst abusievelijk naar art. 1:3) van de Algemene wet bestuursrecht $(\mathrm{Awb})$ is daarmee beperkt volgens de rechtbank.

Hier wordt naar mijn mening ten onrechte een koppeling aangebracht tussen het bestuursrechtelijke belanghebbendebegrip en het civielrechtelijke relativiteitsvereiste. Deze koppeling miskent dat het bestuursrechtelijke belanghebbendebegrip een ontvankelijkheidsvereiste is dat uitgaat van een feitelijk belang: er moet sprake zijn van een rechtstreeks belang bij een besluit. De aard van de betrokken norm speelt daarbij geen rol. Het relativiteitsvereiste wordt daarentegen normatief ingevuld: beoogt de norm bescherming te verlenen? Juist het feit dat het bestuursrechtelijke belanghebbendebegrip geen rekening houdt met het beschermingsoogmerk van de betrokken normen, is reden geweest ook in het bestuursrecht een (vorm van het) relativiteitsvereiste te introduceren.

Het feit dat iemand bestuursrechtelijk geen belanghebbende is bij een besluit, betekent dus geenszins dat anderen geen bescherming kunnen ontlenen aan de normen uit de betreffende wet. Het betekent slechts dat zij geen gebruik kunnen maken van de bestuursrechtelijke kolom van rechtsbescherming, maar hun (vermeende) vorderingen bij de civiele rechter zullen moeten instellen. Daarbij zal de formele rechtskracht van een vergunningbesluit hun niet kunnen worden tegengeworpen, nu er geen bestuursrechtelijke rechtsgang open heeft gestaan voor deze benadeelden.

Overigens is het ook niet juist dat de rechtbank op basis van het feit dat er slechts beperkt administratief beroep is opengesteld, aanneemt dat de kring van belanghebbenden is beperkt. Iemand kan immers belanghebbende zijn in de zin van art. 1:2 Awb zonder dat voor deze belanghebbende administratief beroep openstaat. Deze belanghebbende kan wel degelijk bij de bestuursrechter terecht als hij het niet eens is met het besluit dat wordt genomen na administratief beroep. ${ }^{11}$ Verder staat het deze belanghebbende, voor wie geen administratief beroep openstaat, vrij om bij de bestuursrechter een voorlopige voorziening te vragen ex art. 8:81 Awb.

11. Soms zal dan eerst nog wel bezwaar moeten worden gemaakt (art. 6:8 lid 2 Awb).

\subsection{Ook geen schending van een ongeschreven zorgvuldigheidsnorm}

De rechtbank wijst de vordering van de Slachtoffers ook af voor zover die is gebaseerd op schending van ongeschreven recht. Volgens de rechtbank beschikte PHM, zelfs als zij zich wel had gebaseerd op alle beschikbare informatie, niet over 'geobjectiveerde informatie' die wees op een veiligheidsrisico voor willekeurige derden. De gedachte hierachter is dat uit de gegevens over de Bopz-opname bleek dat deze plaatsvond wegens suïcidaliteit en niet wegens gevaar voor derden. Er valt naar mijn mening wel iets af te dingen op deze redenering. Het systeem van de WWM en CWM, zoals ook vastgesteld door de rechtbank, is dat bij geobjectiveerde geringe twijfel de vergunning moet worden geweigerd. Dit is juist vanuit de gedachte dat een wapen niet in handen moet komen van iemand die, kortweg, in een labiele geestelijke toestand verkeert. Ik zou menen dat als er een indicatie bestaat dat iemand zelfmoordneigingen heeft, wat moet leiden tot weigering van een wapenvergunning, er toch ook redelijkerwijs geobjectiveerde twijfel kan bestaan of deze persoon wel de beschikking moet hebben over een wapen in verband met de risico's voor derden, ook als dit gevaar voor derden (nog) niet expliciet is vastgesteld. Ook de afwijzing van een beroep op schending van een ongeschreven zorgvuldigheidsnorm door PHM wordt pas echt begrijpelijk tegen de achtergrond van de (rechtspolitieke) afweging dat de overheid niet al te snel aansprakelijk zou moeten zijn in dit soort situaties.

\section{Tot slot}

De uitspraak van de rechtbank past in de jurisprudentielijn van de laatste jaren, waarin er bij overheidsaansprakelijkheid streng wordt getoetst aan het relativiteitsvereiste. Er wordt verlangd dat er concrete aanwijzingen zijn te vinden dat de strekking van de geschonden norm is de benadeelden te beschermen. Er wordt in die zaken dus niet uitgegaan van het uitgangspunt dat normen in beginsel strekken tot bescherming van degenen die schade hebben geleden door overtreding van de norm. De achtergrond van deze strenge toets is duidelijk het indammen van een te ver uitdijende overheidsaansprakelijkheid.

Op metaniveau is de uitspraak verdedigbaar vanuit de opvatting dat het niet wenselijk is dat de overheid te ongebreideld aansprakelijk is voor fouten die hun primaire oorzaak hebben in het handelen van een ander. Hoewel er natuurlijk kritiek mogelijk is op deze rechtspolitieke keuze, is het op zichzelf een legitieme keuze. De meer fundamentele vraag is natuurlijk wel hoeveel rechtspolitiek een rechter zou moeten (kunnen) bedrijven en waar het toch eigenlijk meer op de weg van de wetgever zou liggen hier helderheid over te verschaffen.

Los van de verdedigbaarheid van de uitspraak op het abstracte niveau blijft nog wel staan dat de uitspraak ook op het concrete niveau goed moet zijn uit te leggen. Daar wringt het enigszins bij de onderhavige uitspraak. Zonder rekenschap te geven van de rechtspolitieke achtergrond van de afwijzing van 


\section{Maandblad}

relativiteit is het immers niet volledig overtuigend dat de Slachtoffers hier niet zouden vallen onder het beschermingsbereik. Daar komt bij dat niet alle ondersteunde argumenten, zoals de verwijzing naar de (vermeend) beperkte kring van belanghebbenden, even sterk zijn. Hoe dan ook illustreert de uitspraak dat het aansprakelijkheidsbeperkende potentieel van het relativiteitsvereiste volop wordt benut bij de overheidsaansprakelijkheid. 